Jurnal Informatika dan Rekayasa Perangkat Lunak (JATIKA)
Vol. 2, No. 3, September 2021, page-page. 344 352
ISSN 2723-3367
E-ISSN 2797-3492
available online at:htt://jim.teknokrat.ac.id/index.php/informatika

\title{
PERANCANGAN SISTEM PENGELOLAAN DATA PENERIMA DANA ZAKAT, INFAQ DAN SEDEKAH MENGGUNAKAN FRAMEWORK LARAVEL
}

\author{
Syahidan Mushab Al Zikri \\ Universitas Teknokrat Indonesia \\ syahidan_mushab@teknokrat.ac.id
}

\begin{abstract}
Received: (date month year)Accepted: (date month year) Published: (date month year)
Abstract

This research was conducted on the basis of the need for a data management system of zakat, infaq and alms recipients that can be used to manage the utilization data (PDG) on IZI Lampung. In the construction of this system using the waterfall model method, as well as system analysts who run using PIECES analysis. Data collection by way of interviews and observations on IZI Lampung. PIECES analysis is used to make comparisons between the old system and the new system to be created as well as determine the analysis of functional needs, and non-functional needs. This data management system is designed with UML (Unified Modeling Language) system development tools consisting of use case diagrams, activity diagrams, sequence diagrams and class diagrams. In creating this system using mySQL database and text editor sublime text 3 by using laravel framework and PHP programming language. In this system there is a data input system, data search, data editing, data updates and report collection that makes it easier for users to find data, change data and update the desired data.
\end{abstract}

Keywords: Data management, IZI Lampung, Laravel Framework

\begin{abstract}
Abstrak
Penelitian ini dilakukan atas dasar kebutuhan akan adanya suatu sistem pengelolaan data penerima dana zakat, infaq dan sedekah yang dapat digunakan untuk mengelola data bagian pendayagunaan (PDG) pada IZI Lampung. Dalam pembangunan sistem ini menggunakan metode model waterfall, serta analis sistem yang berjalan menggunakan analisis PIECES. Pengumpulan data dengan cara wawancara dan observasi pada IZI Lampung. Analisis PIECES digunakan untuk melakukan perbandingan antara sistem yang lama dengan sistem baru yang akan dibuat serta menentukan analisis kebutuhan fungsional, dan kebutuhan non fungsional. Sistem pengelolaan data ini dirancang dengan alat pengembangan sistem UML (Unified Modeling Language) yang terdiri dari use case diagram, activity diagram, sequence diagram dan class diagram. Dalam membuat sistem ini menggunakan database MySQL dan text editor sublime text 3 dengan menggunakan framework laravel dan bahasa pemrograman PHP. Pada sistem ini terdapat sistem penginputan data, pencarian data, edit data, update data serta pembutan laporan yang memudahkan user dalam mencari data, mengubah data serta memperbaharui data yang diinginkan.
\end{abstract}

Kata Kunci: Pengelolaan data, IZI Lampung, Framework Laravel

To cite this article:

Syahidan Mushab Al Zikri. (2021). PERANCANGAN SISTEM PENGELOLAAN DATA PENERIMA DANA ZAKAT, INFAQ DAN SEDEKAH MENGGUNAKAN FRAMEWORK LARAVEL. Jurnal Informatika dan Rekayasa Perangkat Lunak, Vol(2) No(3), 344-352.

\section{PENDAHULUAN}

Perkembangan teknologi yang semakin cepat menuntut perkembangan pada banyak bidang, salah satunya adalah teknologi informasi (Megawaty et al., 2021; Suri \& Puspaningrum, 2020). Teknologi informasi adalah salah 
satu bidang yang sangat berkaitan dengan perkembangan teknologi. Tanpa adanya teknologi informasi yang mumpuni, kemungkinan perkembangan yang terjadi tidak akan sejauh seperti saat ini. Teknologi informasi adalah suatu studi perancangan, implementasi, pengembangan, dukungan ataupun manajemen sistem informasi dengan basis komputer, khususnya pada aplikasi hardware dan software (Riskiono et al., 2020; Sulistiani, Yuliani, et al., 2021; Yolanda \& Neneng, 2021).

Inisiatif Zakat Indonesia (IZI) secara resmi memperoleh izin operasional sebagai Lembaga Amil Zakat skala nasional melalui surat keputusan Menteri Agama Republik Indonesia no. 423 tahun 2015. Tanggal tersebut menjadi momentum penting lainnya yang menandakan lahirnya Lembaga Amil Zakat Nasional (LAZNAS) IZI, alasan paling penting mengapa IZI dilahirkan adalah adanya tekad yang kuat untuk membangun lembaga pengelola zakat yang otentik. Dengan fokus dalam pengelolaan zakat serta donasi keagamaan lainnya diharapkan IZI dapat lebih sungguh-sungguh mendorong potensi besar zakat menjadi kekuatan real dan pilar kokoh penopang kemuliaan dan kesejahteraan ummat melalui positioning lembaga yang jelas, pelayanan yang prima, efektifitas program yang tinggi, proses bisnis yang efisien dan modern, serta 100\% shariah compliance sesuai sasaran ashnaf dan maqashid tujuan syariah.

IZI dalam berkhidmat bagi ummat sesuai kemiripan pelafalan namanya adalah 'mudah' (easy). Tagline yang diusungnya adalah 'memudahkan, dimudahkan'. Berawal dari keyakinan bahwa jika seseorang memudahkan urusan sesama, maka Allah SWT akan memudahkan urusannya, Insha Allah. Oleh karenanya IZI bertekad untuk mengedukasi masyarakat sehingga meyakini bahwa mengeluarkan zakat itu mudah, membangun infrastruktur pelayanan agar zakat dapat ditunaikan juga dengan mudah, merancang program-program yang efektif yang dapat menghantarkan kehidupan para mustahik agar menjadi jauh lebih mudah. Inilah parameter utama dalam mengukur kinerja pengabdian IZI bagi masyarakat.

IZI cabang lampung saat ini masih menggunakan sistem aplikasi Microsoft excel untuk pengelolaan data penerima dana zakat, infaq dan sedekah nya, mulai dari penginputan pengajuan layanan kemudian perhitungan dana yang sudah di terima oleh penerima manfaat, hingga proses pengelolaan laporan pendayagunaan dana nya. Penggunaan sistem aplikasi ini di rasa masih belum maksimal dalam pengelolaan data nya yang mana mengelola data dalam jumlah yang banyak.

Perancangan Sistem Aplikasi Pengolahan Zakat Berbasis Web. Dimana dalam penelitian yang dilakukan oleh penulis mengangkat masalah pengolahan data yang masih menggunakan aplikasi pengolah kata (word) dan aplikasi pengolah angka (excel) memiliki kekurangan dan kelemahan seperti tidak efektif dalam mengolah datadata dalam jumlah yang banyak, resiko data rusak dan hilang. Selain dari segi pengolahan data, proses transaksi masih dilakukan secara konvensional, segala proses yang berkaitan dengan pemberian dan penerimaan zakat dilakukan di lokasi yakni di Masjid Raya Andalas sehingga dirasa kurang efektif dan efisien, tidak dapat menjangkau muzakki dan mustahik dalam lingkup yang lebih luas dan yang berada jauh dari lokasi. Untuk mengatasi permasalahan di atas, perlu dibangun suatu sistem yang dapat mengkoordinir segala aspek yang berhubungan seperti pengolahan data zakat, pemberi zakat (muzakki), penerima zakat (mustahik) dan berapa jumlah zakat yang harus dikeluarkan. Sistem yang akan dibangun bersifat aplikatif dan online, sehingga segala data dan informasi yang berkaitan tentang BAZ Masjid Raya Andalas dapat diakses oleh orang banyak termasuk oleh muzakki dan mustahik. sistem yang dibangun menyediakan fasilitas bagi administrasi (bagian pengolahan) untuk menginputkan data-data, melakukan perubahan data dan menghapus data-data diinputkan. Laporan karyawan, laporan donasi, laporan penyaluran, laporan mustahik/muzakki dan laporan kas pada Badan Amil Zakat (BAZ) Masjid Raya Andalas (Swara \& Hakim, 2016).

Perancangan Sistem Informasi Zakat Berbasis Web. Dimana dalam penelitian yang dilakukan oleh penulis mengangkat masalah kurangnya informasi tentang zakat dan kurangnya kesadaran masyarakat dalam membayar zakat maka diperlukan suatu badan atau lembaga untuk mengelola zakat. Badan Amil Zakat merupakan suatu lembaga yang menampung dana zakat dari masyarakat yang ingin mengeluarkan zakat atas harta yang dimiliki. Banyaknya data zakat yang harus di catat dari mulai pendaftaran, penerimaan dan penyaluran zakat sehingga menimbulkan berbagai permasalahan yaitu kehilangan data, maka perancangan sistem informasi pengelolaan zakat berbasis web salah satu cara untuk mengatasi permasalahan dan kelemahan dari proses pengelolaan zakat. Pada Website ini akan menampilkan informasi tentang zakat, layanan perhitungan zakat, layanan pembayaran zakat secara online dengan konfirmasi pembayarannya berguna untuk mempermudah masyarakat dalam melaksanakan pembayaran zakat, dan dengan website ini mempermudah bagian keuangan dalam melakukan proses pengelolaan zakat, serta dengan sistem yang sudah terkomputerisasi dapat tercapai suatu kegiatan yang efektif dan efisien dalam menunjang aktifitas pada Badan Amil zakat ini (Supriadi \& Fitriani, 2018).

Permasalahan yang ada dalam sistem ini adalah tampilan penginputan data yang kurang efektif dan efisien, membutuhkan waktu untuk pencarian data yang tersimpan di dalam folder-folder penyimpanan data di komputer, tidak dapat melihat secara visual progres perkembangan data, belum adanya sistem informasi online yang terpusat 
untuk bisa di akses kapan saja dan di mana saja untuk mempercepat dan mempermudah dalam mendapatkan informasi data penerima dana zakat, infaq dan sedekah di IZI cabang lampung. IZI cabang lampung menginginkan sistem pengelolaan data yang bisa menggantikan sistem yang sudah ada saat ini, dengan harapan kemudahan dan kecepatan dalam mengelola data.

\section{METODE PENELITIAN} Kerangka Penelitian

Kerangka penelitian pada dasarnya adalah kerangka hubungan antara konsep-konsep yang ingin diamati atau diukur melalui penelitian yang akan dilakukan (Alita et al., 2020; Surahman et al., 2020). Berikut ini adalah gambar kerangka penelitian yang digunakan penulis dapat dilihat pada gambar 1 .

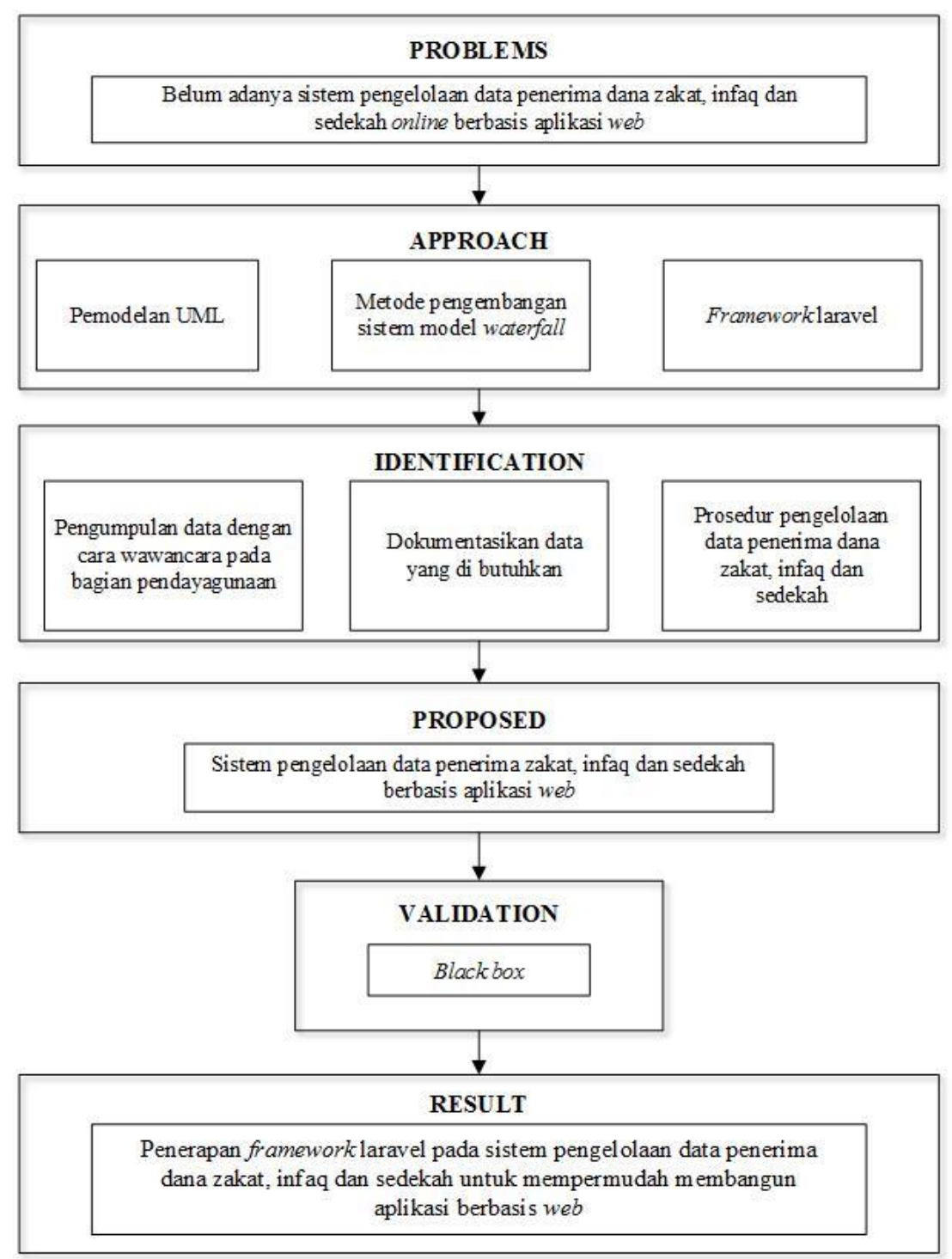

Gambar 3.1 Kerangka penelitian

\section{Teknik Pengumpulan Data}


Dalam suatu penelitian, data merupakan salah satu komponen yang paling penting untuk menunjang keberhasilan penelitian. Data yang digunakan pun harus data yang benar-benar baik. Data yang baik akan didapatkan jika dikumpulkan dengan teknik yang baik (Ariyanti et al., 2020; Febrina \& Megawaty, 2021; Surahman et al., 2021). Metode pengumpulan data pada penelitian ini meliputi :

1. Observasi (Observation)

Metode pengumpulan data dilakukan dengan cara pengamatan di IZI Lampung pada bagian pendayagunaan hal itu dilakukan dengan maksud untuk mendapatkan data dan dokumen secara langsung yang benar-benar terjadi didalam pelaksanaan atau proyek.

2. Wawancara (Interview)

Metode pengumpulan data atau informasi dilakukan dengan cara bertanya langsung kepada bapak Adriansyah, SE sebagai staff pendayagunaan, wawancara di lakukan pada hari senin, 06 Agustus 2018.

3. Tinjauan Pustaka (Literature Review)

Metode pengumpulan data dilakukan dengan cara mempelajari berbagai jurnal ilmiah dan dokumen atau sumber bacaan serta buku - buku yang berkaitan atau berhubungan dengan topik usulan penelitian.

4. Dokumentasi (Documentation)

Metode pengumpulan data dilakukan dengan cara mengumpulkan beberapa dokumentasi yang diperlukan dalam penelitian ini berupa photo pada saat wawancara dan data penerima bantuan.

\section{Metode Analisis}

metode PIECES adalah metode analisis sebagai dasar untuk memperoleh pokok-pokok permasalahan yang lebih spesifik. Dalam menganalisis sebuah sistem, biasanya akan dilakukan terhadap beberapa aspek antara lain adalah kinerja, informasi, ekonomi, keamanan aplikasi, efisiensi dan pelayanan pelanggan. Analisis ini disebut dengan PIECES Analysis (Performance, Information, Economy, Control, Eficiency and Service).

Tabel 1. Analisis PIECES

\begin{tabular}{|c|c|c|c|}
\hline No & Kategori & $\begin{array}{l}\text { Kelemahan } \\
\text { Sistem Lama }\end{array}$ & Sistem Usulan \\
\hline 1 & Performance (Kinerja) & $\begin{array}{l}\text { Sistem yang ada saat ini belum optimal } \\
\text { untuk kinerja yang di hasilkan nya, } \\
\text { karena saat ini masih sering ada } \\
\text { kesalahan dan kurang cepat dalam } \\
\text { pengelolaan data }\end{array}$ & $\begin{array}{l}\text { Sistem yang diajukan sangat } \\
\text { membantu kinerja sistem } \\
\text { pengelolaan data agar lebih cepat } \\
\text { dan tersistem untuk mengurangi } \\
\text { resiko kesalahan }\end{array}$ \\
\hline 2 & Information (Informasi) & $\begin{array}{l}\text { Sistem yang ada saat ini infomasi } \\
\text { pengelolaan datanya masih bersifat } \\
\text { offline jadi belum optimal untuk } \\
\text { mendapatkan informasi yang real time } \\
\text { dan update }\end{array}$ & $\begin{array}{l}\text { Sistem yang diajukan akan } \\
\text { mempermudah } \\
\text { mendapatkan untuk } \\
\text { pengelolaan data yang cepat, } \\
\text { real time dan update karena bisa } \\
\text { di akses melalui internet (online) }\end{array}$ \\
\hline 3 & Economy (Ekonomi) & $\begin{array}{l}\text { Sistem yang ada saat ini tidak terlalu } \\
\text { banyak menggunakan biaya, tapi jika } \\
\text { data nya hilang atau rusak maka akan } \\
\text { mengakibatkan adanya biaya tambahan. }\end{array}$ & $\begin{array}{l}\text { Sistem yang diajukan untuk di } \\
\text { awal harus membutuhkan biaya } \\
\text { yang cukup banyak, tapi sangat } \\
\text { berimbang dengan manfaat dan } \\
\text { fasilitas nya di berikan }\end{array}$ \\
\hline 4 & Control (Pengendalian) & $\begin{array}{l}\text { Sistem yang ada saat ini belum adanya } \\
\text { sistem control untuk menjaga keamanan } \\
\text { data dan kesalahan dalam proses } \\
\text { melakukan pengelolaan data }\end{array}$ & $\begin{array}{l}\text { Sistem yang diajukan akan } \\
\text { mempunyai sistem control yang } \\
\text { mana bisa menjaga keamanan } \\
\text { data dan meminimalisir } \\
\text { terjadinya kesalahan. }\end{array}$ \\
\hline 5 & Efficiency (Efisiensi) & $\begin{array}{l}\text { Sistem yang ada saat ini pengelolaan } \\
\text { data nya masih kurang efisien dalam } \\
\text { pembuatan laporan yang di lakukan satu } \\
\text { bulan sekali }\end{array}$ & $\begin{array}{l}\text { Sistem yang diajukan lebih } \\
\text { efesien dalam pengelolaan data } \\
\text { nya karena memberikan } \\
\text { kemudahkan dalam pembuatan } \\
\text { laporan }\end{array}$ \\
\hline
\end{tabular}




\begin{tabular}{|l|l|l|l|}
\hline 6 & Service (Pelayanan) & $\begin{array}{l}\text { Sistem yang ada saat ini masih belum } \\
\text { optimal untuk memberikan pelayanan }\end{array}$ & $\begin{array}{l}\text { Sistem yang diajukan akan } \\
\text { memberikan pelayanan yang } \\
\end{array}$ \\
& $\begin{array}{l}\text { pengelolan data nya karena masih di } \\
\text { baik dalam proses pengelolaan }\end{array}$ \\
& $\begin{array}{l}\text { lakukan secara offline yang } \\
\text { menyebabkan kurang cepat untuk } \\
\text { mendapatkan sebuah informasi }\end{array}$ & $\begin{array}{l}\text { online jadi bisa lebih cepat untuk } \\
\text { mendapatkan sebuah informasi }\end{array}$ \\
\hline
\end{tabular}

\section{HASIL DAN PEMBAHASAN}

Implementasi sistem adalah langkah-langkah atau prosedur-prosedur yang dilakukan dalam menyelesaikan desain sistem yang telah disetujui, untuk menginstal, menguji dan memulai sistem baru atau sistem yang diperbaiki (Darwis et al., 2021; Irvansyah et al., 2020; Isnian \& Suaidah, 2016). Tahap implementasi sistem merupakan tahap meletakkan sistem supaya siap untuk dioperasikan (Anggraini et al., 2020; Nurkholis et al., 2021; Sucipto et al., 2021). Tahap ini termasuk juga kegiatan menulis kode program jika tidak digunakan paket perangkat lunak aplikasi (Agustina \& Isnaini, 2020; Riswanda \& Priandika, 2021; Setiawansyah et al., 2021; Sulistiani, Sulistiyawati, et al., 2021).

\section{Tampilan Halaman Home}

Halaman ini merupakan halaman pertama kali yang akan tampil setelah kita ketik link url nya di brouser. Berikut ini adalah gambar tampilan halaman home dapat di lihat pada gambar 2.

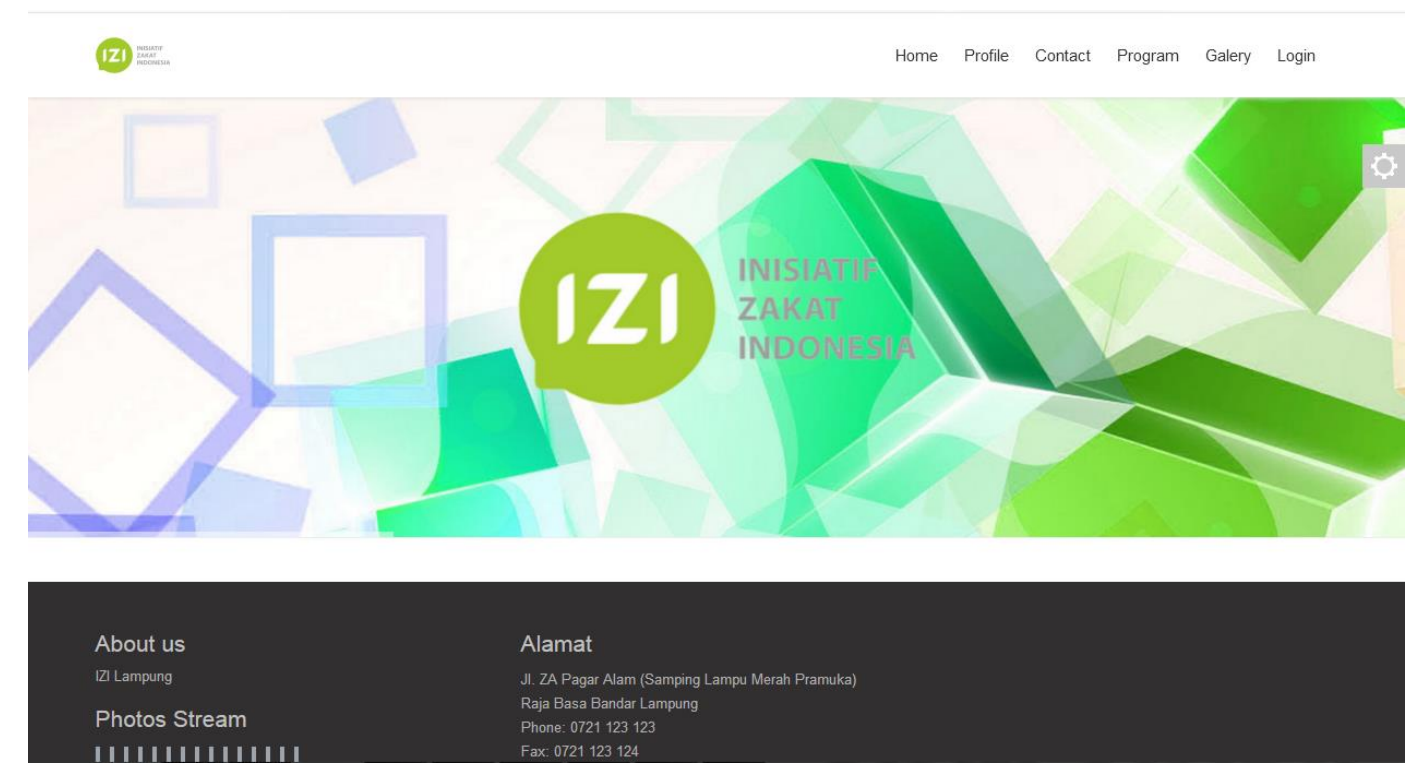

Gambar 2. Tampilan Halaman Home

\section{Tampilan Halaman Form Login User}

Halaman ini merupakan validasi awal apakah kita mempunyai hak akses atau tidak pada sistem ini untuk masuk kedalam menu utama setelah berhasil log in, agar bisa log in kia harus memasukan e-mail dan password yang sudah di buat sebelumnya oleh user dengan benar. Berikut ini adalah gambar tampilan halaman log in user dapat di lihat pada gambar 3 . 


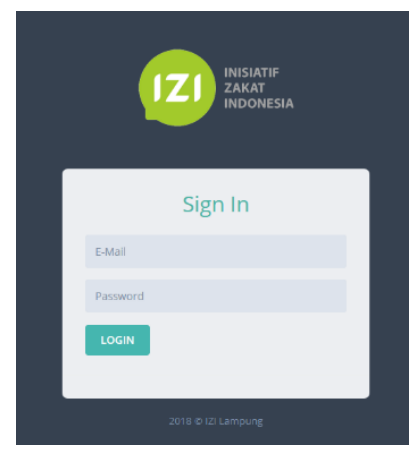

\section{Gambar 3. Tampilan Halaman Login User}

\section{Tampilan Halaman PDG Form Menu Dashboard}

Pada halaman ini merupakan halaman yang pertama kali akan tampil setelah kita berhasil log in dan akan menampilkan beberapa pilihan menu diantaranya : menu dashboard, menu master data, menu laporan dan menu grafik. Adapun informasi jumlah data dan total bantuan lamus, lapors, latahzan, kaki palsu dan RSP. Berikut ini adalah gambar tampilan halaman PDG menu dashboard dapat di lihat pada gambar 4.

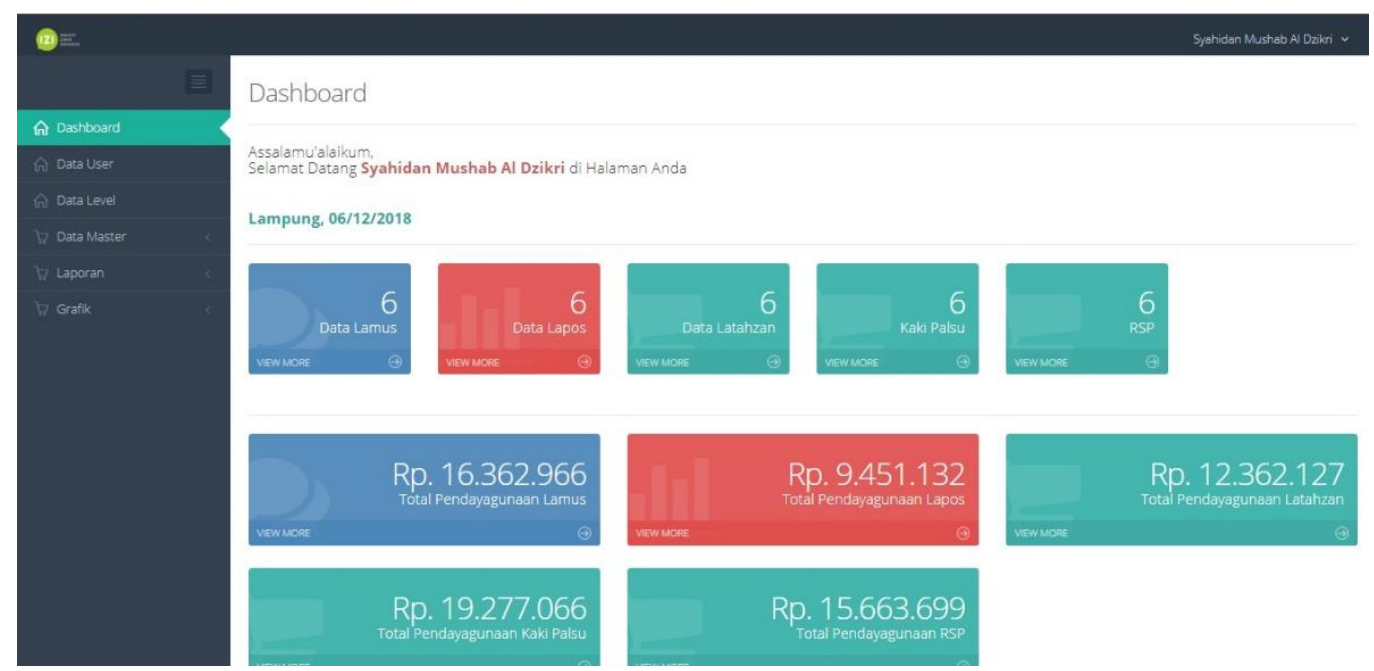

Gambar 4. Tampilan Halaman PDG Menu Dashboard

\section{Tampilan Halaman PDG Form Menu Master Data Lamus}

Pada halaman ini PDG bisa menambah, mengedit, melihat detail, melihat list dan menghapus data lamus.. Berikut ini adalah gambar tampilan halaman PDG form menu master data lamus dapat di lihat pada gambar 5.8 dan 5 .

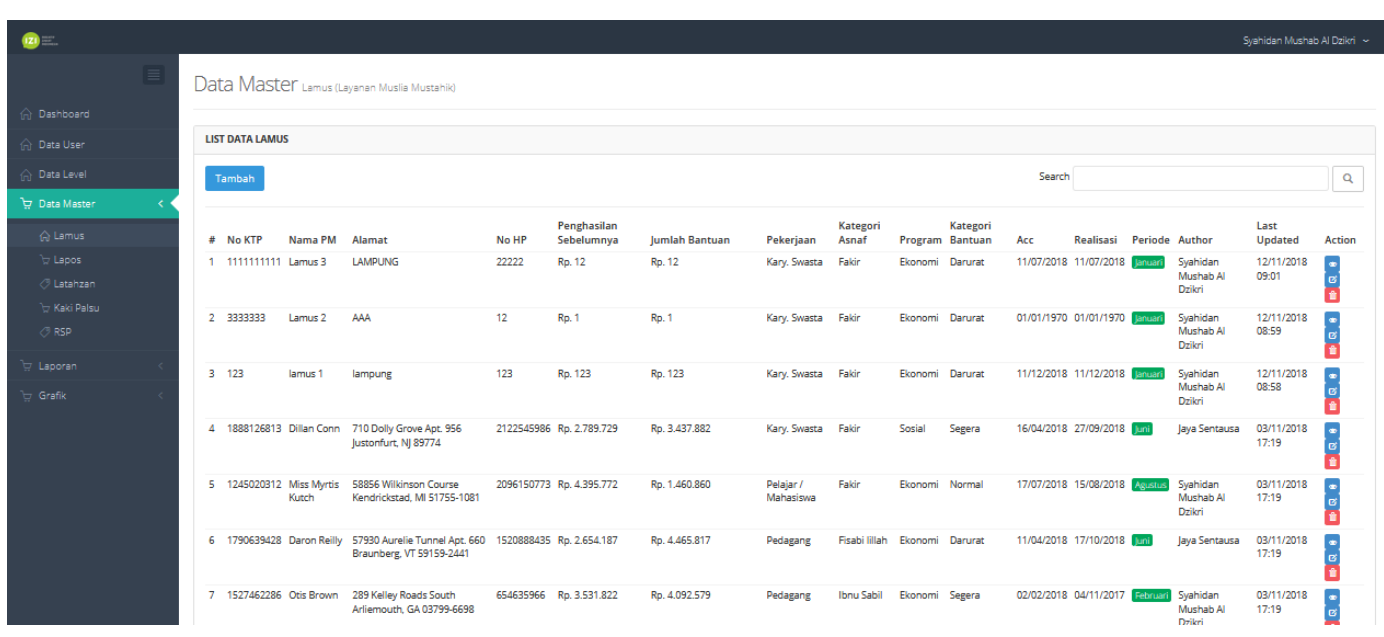




\section{Gambar 5. Tampilan Halaman PDG Form Menu Master Data Lamus}

\section{Tampilan Halaman PDG Form Menu Master Data Lapors}

Pada halaman ini PDG bisa menambah, mengedit, melihat detail, melihat list dan menghapus data lapors.. Berikut ini adalah gambar tampilan halaman PDG form menu master data lapors dapat di lihat pada gambar 5.10 dan 6.

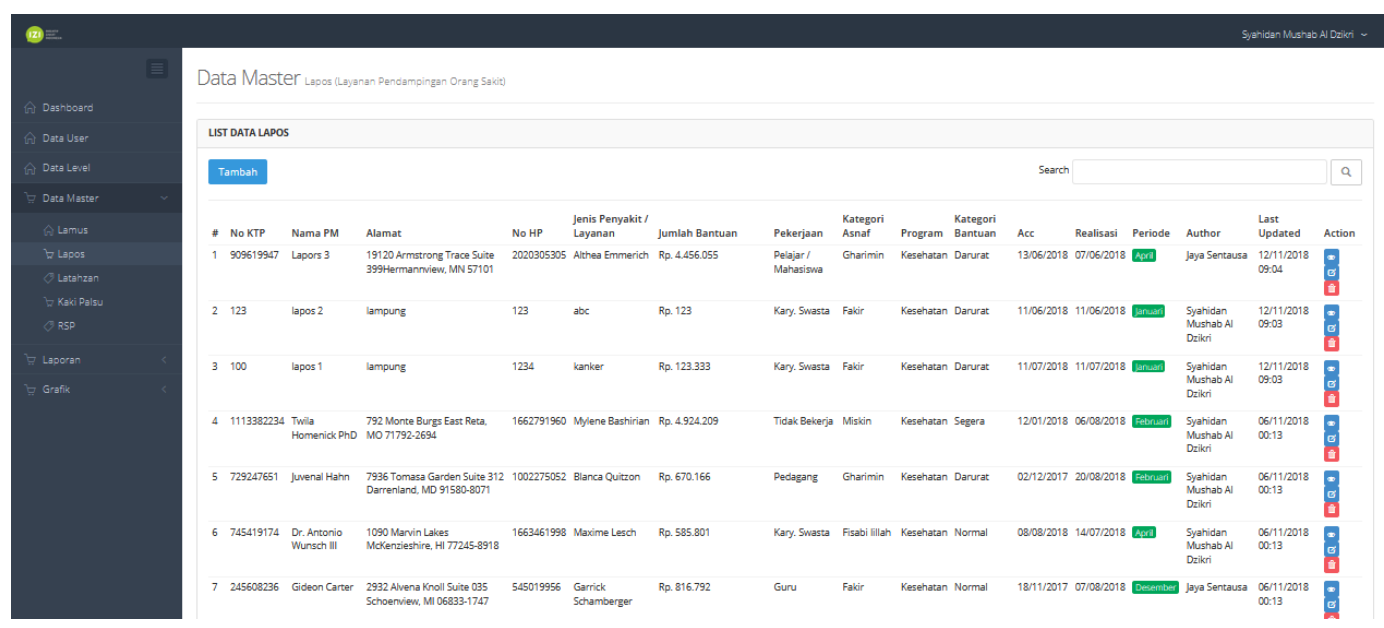

Gambar 6. Tampilan Halaman PDG Form Menu Master Data Lapors

\section{Tampilan Halaman PDG Form Menu Master Data Latahzan}

Pada halaman ini PDG bisa menambah, mengedit, melihat detail, melihat list dan menghapus data latahzan.. Berikut ini adalah gambar tampilan halaman PDG form menu master data latahzan dapat di lihat pada gambar 7.

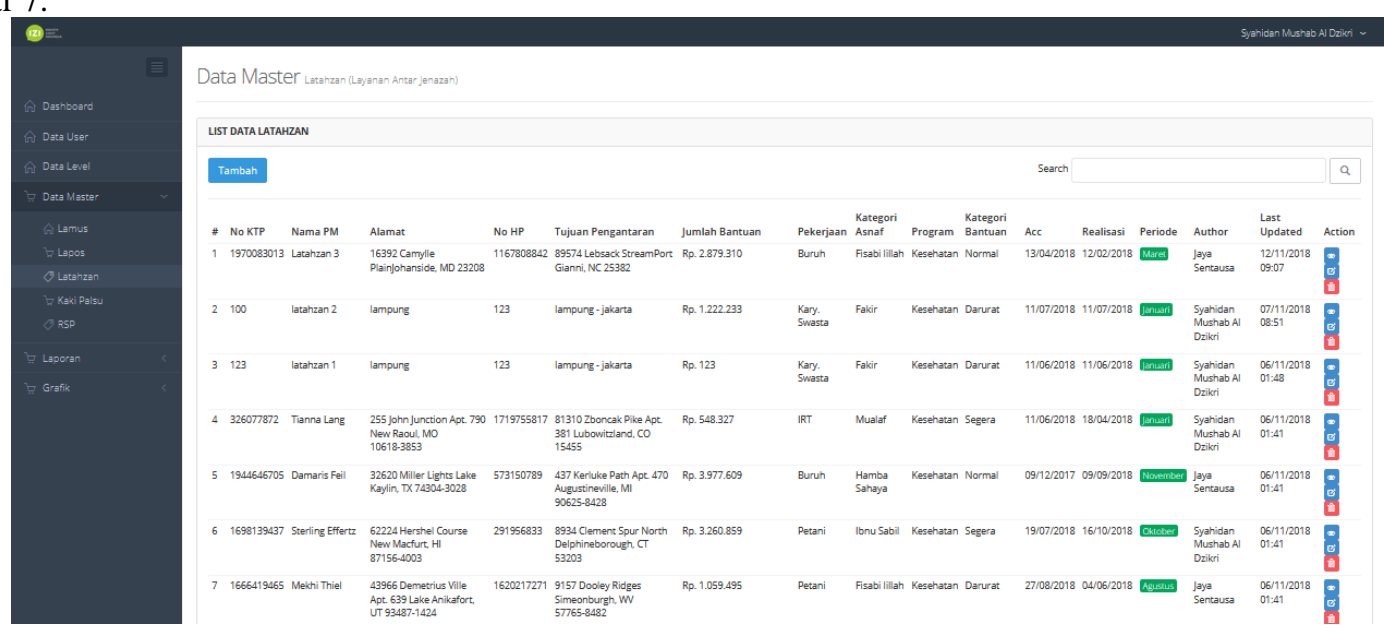

Gambar 7. Tampilan Halaman PDG Form Menu Master Data Latahzan

\section{Hasil Analisis}

Dari analisis yang sudah di lakukan, sistem yang diusulkan pada sistem pengelolaan data penerima dana zakat, infaq dan sedekah di IZI Lampung dapat di ambil hasil sebagai berikut Penggunaan media online dapat mempermudah dalam mendapatkan informasi data penerima dana zakat, infaq dan sedekah pada IZI Lampung. Penggunaan aplikasi web akan memaksimalkan proses pengelolaan data penerima dana zakat, infaq dan sedekah pada IZI Lampung agar lebih mudah proses penginputan data, pencarian data dan pembuatan laporan nya.

\section{Kontribusi}


Dari penelitian yang sudah di lakukan, sistem yang diusulkan pada sistem pengelolaan data penerima dana zakat, infaq dan sedekah di IZI Lampung dapat memberikan kontribusi sebagai berikut Memberikan kemudahan pada saat proses pengelolaan penginputan data penerima dana zakat, infaq dan sedekah serta pencarian data dan juga pembuatan laporan nya. Bagian bidang PDG tidak harus mengirim data kepada pimpinan, karena data sudah ada di database internet, sehingga pimpinan bisa melihat informasi data kapan saja dan di mana saja menggunakan smartphone atau komputer. Dengan adanya sistem ini diharapkan bisa membantu proses pengelolaan data penerima dana zakat, infaq dan sedekah pada IZI Lampung menjadi lebih baik lagi.

\section{SIMPULAN}

Hasil pembahasan mengenai perancangan, implementasi dan pengujian sistem pengelolaan data penerima dana zakat, infaq dan sedekah di IZI Lampung dapat disimpulkan sebagai berikut Sistem yang di bangun menggunakan framewok laravel untuk mengelola data penerima dana zakat, infaq dan sedekah untuk mempermudah membangun aplikasi berbasis web. Menggunakan alat pengembangan sistem UML (Unified Modeling Language) yang terdiri dari usecase diagram, activity diagram, squence diagram dan class diagram. Menggunakan database MySQL dan tools Sublime Text 3 dan bahasa pemrograman PHP. Sistem dapat mengelola data penerima layanan dengan cepat mulai dari penginputan data sampai pembuatan laporan nya. Sistem dapat melakukan pencarian data dengan cara mengetik record yang sudah ada di database pada form pencarian data. Sistem dapat menampilkan data dalam bentuk visual grafik. Sistem dapat di akses online oleh PDG dan pimpinan melalui media layanan internet (browser) dari komputer atau smartphone untuk mempercepat dan mempermudah dalam mengelola data dan mendapatkan informasi.

\section{REFERENSI/DAFTAR PUSTAKA}

Agustina, I., \& Isnaini, F. (2020). Sistem Perhitungan dan Pelaporan Pajak Penghasilan Pasal 21 pada Universitas XYZ. Jurnal Ilmiah Infrastruktur Teknologi Informasi (JIITI), 1(2), 24-29.

Alita, D., Tubagus, I., Rahmanto, Y., Styawati, S., \& Nurkholis, A. (2020). Sistem Informasi Geografis Pemetaan Wilayah Kelayakan Tanam Tanaman Jagung Dan Singkong Pada Kabupaten Lampung Selatan. Journal of Social Sciences and Technology for Community Service (JSSTCS), 1(2).

Anggraini, Y., Pasha, D., \& Damayanti, D. (2020). SISTEM INFORMASI PENJUALAN SEPEDA BERBASIS WEB MENGGUNAKAN FRAMEWORK CODEIGNITER. Jurnal Teknologi Dan Sistem Informasi, 1(2), 64-70.

Ariyanti, L., Satria, M. N. D., \& Alita, D. (2020). SISTEM INFORMASI AKADEMIK DAN ADMINISTRASI DENGAN METODE EXTREME PROGRAMMING PADA LEMBAGA KURSUS DAN PELATIHAN. Jurnal Teknologi Dan Sistem Informasi, 1(1), 90-96.

Darwis, D., Siskawati, N., \& Abidin, Z. (2021). Penerapan Algoritma Naive Bayes Untuk Analisis Sentimen Review Data Twitter Bmkg Nasional. Jurnal Tekno Kompak, 15(1), 131-145.

Febrina, C. A., \& Megawaty, D. A. (2021). APLIKASI E-MARKETPLACE BAGI PENGUSAHA STAINLESS BERBASIS MOBILE DI WILAYAH BANDAR LAMPUNG. Jurnal Teknologi Dan Sistem Informasi, 2(1), 15-22.

Irvansyah, F., Muhaqiqin, \& Setiawansyah. (2020). Aplikasi pemesanan jasa cukur rambut berbasis android. 1(1), 26-32.

Isnian, A. R., \& Suaidah, Y. T. U. (2016). Sistem Pendukung Keputusan Penerimaan Asisten Dosen Pada Perguruan Tinggi Teknokrat Menggunakan Metode Analytical Hierarchy Process (AHP). Jupiter, 2(1).

Megawaty, D. A., Setiawansyah, S., Alita, D., \& Dewi, P. S. (2021). Teknologi dalam pengelolaan administrasi keuangan komite sekolah untuk meningkatkan transparansi keuangan. Riau Journal of Empowerment, 4(2), 95-104.

Nurkholis, A., Susanto, E. R., \& Wijaya, S. (2021). Penerapan Extreme Programming dalam Pengembangan Sistem Informasi Manajemen Pelayanan Publik. J-SAKTI (Jurnal Sains Komputer Dan Informatika), 5(1), 124-134.

Riskiono, S. D., Susanto, T., \& Kristianto, K. (2020). Augmented reality sebagai Media Pembelajaran Hewan Purbakala. Krea-TIF, 8(1), 8-18.

Riswanda, D., \& Priandika, A. T. (2021). ANALISIS DAN PERANCANGAN SISTEM INFORMASI MANAJEMEN PEMESANAN BARANG BERBASIS ONLINE. Jurnal Informatika Dan Rekayasa Perangkat Lunak, 2(1), 94-101.

Setiawansyah, S., Adrian, Q. J., \& Devija, R. N. (2021). Penerapan Sistem Informasi Administrasi Perpustakaan 
Menggunakan Model Desain User Experience. Jurnal Manajemen Informatika (JAMIKA), 11(1), 24-36. Sucipto, A., Adrian, Q. J., \& Kencono, M. A. (2021). Martial Art Augmented Reality Book (Arbook) Sebagai Media Pembelajaran Seni Beladiri Nusantara Pencak Silat. Jurnal Sisfokom (Sistem Informasi Dan Komputer), 10(1), 40-45.

Sulistiani, H., Sulistiyawati, A., \& Hajizah, A. (2021). Perancangan Sistem Pengelolaan Keuangan Komite Menggunakan Web Engineering (Studi Kasus: SMK Negeri 1 Gedong Tataan). Komputika: Jurnal Sistem Komputer, 10(2), 163-171.

Sulistiani, H., Yuliani, A., \& Hamidy, F. (2021). Perancangan Sistem Informasi Akuntansi Upah Lembur Karyawan Menggunakan Extreme Programming. Technomedia Journal, 6(01 Agustus).

Supriadi, D., \& Fitriani, L. (2018). Perancangan sistem informasi zakat berbasis web. IJCIT (Indonesian Journal on Computer and Information Technology), 3(1).

Surahman, A., Wahyudi, A. D., Putra, A. D., Sintaro, S., \& Pangestu, I. (2021). Perbandingan Kualitas 3D Objek Tugu Budaya Saibatin Berdasarkan Posisi Gambar Fotogrametri Jarak Dekat. InfoTekJar: Jurnal Nasional Informatika Dan Teknologi Jaringan, 5(2).

Surahman, A., Wahyudi, A. D., \& Sintaro, S. (2020). Implementasi Teknologi Visual 3D Objek Sebagai Media Peningkatan Promosi Produk E-Marketplace.

Suri, M. I., \& Puspaningrum, A. S. (2020). SISTEM INFORMASI MANAJEMEN BERITA BERBASIS WEB. Jurnal Teknologi Dan Sistem Informasi, 1(1), 8-14.

Swara, G. Y., \& Hakim, D. (2016). Perancangan Sistem Aplikasi Pengolahan Zakat Berbasis Web (Studi Kasus: Badan Amil Zakat Masjid Raya Andalas Kota Padang). Jurnal Teknoif ITP, 4(1), 32-39.

Yolanda, S., \& Neneng, N. (2021). Rancang Bangun Sistem Informasi untuk Perhitungan Biaya Sewa Kontainer Pada PT Java Sarana Mitra Sejati. Jurnal Ilmiah Sistem Informasi Akuntansi, 1(1), 24-34. 